\title{
Uma conspiração multidimensional em torno da indústria de software: argumentos para a intervenção em setores de alta intensidade tecnológica*
}

Silvio Vanderlei Araújo

Universidade Federal da Bahia (UFBA)

Alisson Santos de Sousa

Secretaria de Ciência, Tecnologia e Inovação do Estado da Bahia

Emerson Wilian Araújo

Fundação Visconde de Cairu

\begin{abstract}
RESUMO
Este artigo analisa o debate atual relacionado à intervenção estatal nas indústrias de alta intensidade tecnológica. Por um lado, existem argumentos contra tais intervenções que consideram essas indústrias setores também intensivos em capital. Ao contrário do que se pensa, para esta corrente, a intensidade de capital - e não a tecnológica - seria o fator determinante da adição de valor. Por ouro lado, foi possível provar, neste trabalho, que existe ao menos uma indústria de alta intensidade tecnológica, intensiva em trabalho e não em capital, com alto valor adicionado, que gera diversas externalidades positivas em âmbitos social e econômico: a indústria de software. Tais externalidades servem como importantes argumentos para justi-
\end{abstract}

Gostaríamos de registrar os nossos sinceros agradecimentos pelas contribuições dos pareceristas da RBI, as quais foram bastante pertinentes e importantes para o fortalecimento do objeto deste artigo. 
ficar a intervenção estatal em setores de alta intensidade tecnológica e lança dúvidas sobre o argumento da exclusividade do capital como determinante de adição de valor.

Palavras-Chave | Vantagens Comparativas; Indústria de Software; Intervenção Estatal; Paul Krugman

Códigos JEL | O25; L86

\section{A multidimensional conspiracy around the software industry: arguments for intervention in high technology sectors}

ABSTRACT

This paper analyses the current debate about governmental intervention in high tech industries. On one hand, there are arguments against such interventions that consider the high tech industries as a capital intensive sector; instead of technological intensity, the capital intensity determines the value added. On the other hand, we could prove that there is at least one high tech industry, which is job intensive and non capital intensive, with high value added, that generates several positive externalities (the software industry). Such externalities are important arguments to support governmental intervention in high tech industries and cast doubts on the capital's value added argument.

KEYWORDS | Comparative Advantages; Software Industry; State Intervention; Paul Krugman

JEL-CODES | 025; L86 


\section{Introdução}

Uma boa forma de iniciar este trabalho é compartilhando com o leitor a ideia de Peter Evans sobre o Estado e o desenvolvimento, afirmando que todos os Estados são intervencionistas. Ao estudar as formas de intervenção para a promoção de desenvolvimento e transformação industrial, Evans (2004, p. 115) observou que

todos os estados formulam regras e tentam fazer com que elas se cumpram. Salvo acordos completamente negativos, qualquer grupo de regras consistentes e previsiveis torna-se um bem coletivo. Construir e fazer com que as regras se cumpram é uma função que mesmo o estado mais minimalista não pode evitar.

Intervir para o desenvolvimento econômico é uma forma legítima que o Estado assume para cumprir seu papel clássico de sobrevivência militar, ordem interna, autonomia e soberania. O desenvolvimento, portanto, é um ótimo pré-requisito para a garantia de bem-estar no longo prazo. Entretanto, o esplendor da intervenção estatal não se encontra em definir o quanto o é Estado intervencionista, mas, sobretudo, em determinar as formas e os papéis por ele assumidos.

Peter Evans tinha o interesse específico de demonstrar a tese de que o Estado, para ser bem-sucedido, precisa combinar dois ingredientes fundamentais: autonomia e parceria. Autonomia no sentido da capacidade de implementar os planos desenvolvimentistas com certa independência dos interesses privados (até certo ponto para não se ter um insulamento) e parceria como instrumento informativo e direcionador das ações de desenvolvimento promovidas pela burocracia estatal.

O autor observa, ainda, que haveria de ser escolhido o setor ideal para se testar sua hipótese. Citando Albert Hirschman (1977, p.96), Peter Evans (2004, p. 32) destaca que

alguns setores criam uma "conspiração multidimensional" a favor do desenvolvimento, induzindo sinergias empresariais, criando externalidades positivas para o resto da economia e moldando interesses de grupos politicos numa coalização desenvolvimentista. Nichos na divisão internacional do trabalho são desejáveis não somente porque podem trazer maiores lucros e permitir uma acumulação mais rápida de capital, mas também porque facilitam o avanço dos objetivos sociais e de bem-estar associados ao "desenvolvimento" no sentido mais amplo do termo.. 
Uma indústria candidata a ser o expoente para o surgimento de uma "conspiração multidimensional" precisa, por exemplo, reunir diversos fatores que a tornem uma oportunidade legítima para tal empreitada. Características relacionadas à intensidade tecnológica (maior lucratividade por conta da possibilidade de inovação), à aplicação intensiva de mão de obra (objetivos sociais), à convergência tecnológica (promoção de sinergias e externalidades) e à adição de valor sobre capital e trabalho (acumulação mais rápida de capital) representam uma excelente combinação em favor do desenvolvimento e, consequentemente, do bem-estar no longo prazo.

Tais qualidades, por se comportarem como requisitos desejáveis e impulsionadores de interesses, servem de guias de avaliação de setores que possam constituir singularidades para o redimensionamento da divisão internacional do trabalho e introduzir algumas economias periféricas no cenário da produção de bens mais dinâmicos e lucrativos.

Porém, uma leitura da obra de Paul Krugman e Maurice Obstfeld (1999) permite identificar dois argumentos que contestam a ideia de uma "conspiração multidimensional” em torno das indústrias de alto valor adicionado. O primeiro remete às limitações identificadas segundo a teoria das vantagens comparativas, que impediriam nações subdesenvolvidas a realizarem o catching-up em suas indústrias; e o segundo refere-se às restrições sobre a adição de valor nas indústrias de alta tecnologia, que se dariam, essencialmente, por conta da alta intensidade de capital, algo que também limita a intervenção em economias periféricas.

Tem-se um impasse estabelecido: correntes desenvolvimentistas que veem na indústria de alta tecnologia um campo profícuo para os esforços de desenvolvimento; e correntes mais cautelosos que consideram precipitada uma incursão nessa indústria, levando-se em conta a avaliação do valor e os pressupostos da teoria das vantagens comparativas.

A proposta deste trabalho, entretanto, não se trata da comprovação ou refutação inquestionável dos argumentos favoráveis ou contrários à opção de desenvolvimento via indústria de alta tecnologia. Sobretudo, espera-se reunir elementos que subsidiem uma avaliação da força explicativa dos mesmos enquanto propostas de incursão de esforços desenvolvimentistas nesse tipo de indústria. Além disso, não se tem a intenção de esgotar as discussões a respeito do tema e, pelo contrário, espera-se que este seja um ponto de partida para esforços investigativos mais aprofundados.

Contudo, há razões para sustentar a tese de que o setor de software - que subsidiará as análises empíricas deste trabalho - pode reunir condições para moldar uma articulação multi-institucional desenvolvimentista, por conta de suas características 
de convergência e intensidade tecnológica, adição de valor e emprego intensivo de trabalho, em detrimento daqueles relacionados ao capital. Tem-se aí a tese principal deste trabalho.

Na seção 2, apresentam-se evidências de que os Estados realmente intervêm em prol da indústria de alta tecnologia, de forma específica na de TI, o que ocorre por uma necessidade de promoção de catching-up. $\mathrm{O}$ argumento contrário à ideia sobre a adição de valor como elemento de justificativa sobre a decisão de investimento em setores de alta tecnologia é explicitado na seção 3. Além disso, são abordados, na seção 4, os subsídios que demonstram a possibilidade de intervenção nas regras da vantagem comparativa, por meio da análise das indústrias de software no Brasil e nos EUA. Não serão estabelecidos contrapontos especulativos sobre as diferenças entre as indústrias dos dois países, mas pode-se perceber, pelo isolamento do efeito país, que, independente das condiçốes do ambiente, é possível se prover à indústria características desejáveis para transformá-la num motor de desenvolvimento. Logo, sustenta-se a tese aqui apresentada como forma de subsidiar o debate sobre as prioridades de investimentos em setores industriais de alta tecnologia. Por fim, insere-se uma seção de conclusão.

\section{0 Estado intervencionista: quais as formas de intervenção e por que o eEstados interviriam na indústria de alta intensidade tecnológica?}

Rosenberg e Birdzell (1986) consideram que o crescimento econômico ocidental foi marcado historicamente por pequenas taxas repetitivas, por diversas inovaçōes tecnológicas e, essencialmente, pelo apoio de inúmeras instituições, principalmente as governamentais. Para esses autores, a transformação econômica do mundo industrial e o consequente crescimento econômico só foram possíveis devido ao desenvolvimento concomitante das instituiçôes de apoio, tais como as agências reguladoras, as agências de comércio, o advento da organização fabril, a estrutura jurídica nacional e internacional, as concessionárias de serviços públicos, as políticas, entre outros.

Além disso,

pode-se partir da simples constatação empírica de que não é possivel encontrar na história qualquer exemplo de um processo de desenvolvimento inserido em um ambiente que se assemelhe, ainda que vagamente, às histórias de interaçôes econômicas desvinculadas de instituiçôes, encontráveis em boa parte da teoria eco- 
nômica contemporânea. Ao contrário, todas as experiências históricas de crescimento econômico sustentado - desde pelo menos a "Revolução Industrial" inglesa - têm encontrado as condiçôes que as tornam possiveis dentro de um rico conjunto de instituiçôes complementares, normas de comportamento compartilhadas e politicas públicas (CIMOLI et al., 2007, p.57).

Quanto à parte do Estado, existe uma necessidade em intervir sobre a iniciativa empreendedora, o que denota a este um poder considerável, manifestado por meio dos incentivos à atividade econômica que, entretanto, carecem de esforços para a superação dos obstáculos estruturais para o desenvolvimento. Na visão de Prebisch (1964, p.78), o Estado deve intervir:

$i$ - porque o mercado nem sempre dá indicaçôes que promovam o emprego mais econômico dos recursos disponiveis; e ii - [...] porque as indicaçôes dadas pelas forças do mercado só concernem a uma parte das decisóes dos indivíduos, e não a todas, e especialmente a algumas que têm importância considerável no desenvolvimento. A intervenção do Estado é essencial para guiar a atividade privada, para levá-lasem compulsão alguma - ao cumprimento de certos objetivos do desenvolvimento.

A questão é: quais os objetivos, então? A leitura da obra de Prebisch sugere claramente o alinhamento entre objetivos econômicos, sociais e políticos, sem o que se torna inócua a ação do Estado. Essas seriam justificativas contundentes para uma ação intervencionista em prol do desenvolvimento. Se esses são os objetivos, quais as formas de materialização da intervenção?

Mody (1989, p.51), por exemplo, destaca algumas ações historicamente executadas pelos Estados para a promoção do setor de TI: proteção à indústria infante; promoção de transbordamento tecnológico; e imposição de barreiras à entrada para investidores estrangeiros (Quadro 1).

Essas açōes possuem lugar na história e no espaço como atitudes desenvolvimentistas legítimas, que, porém, admitem alguma questionabilidade. O que se discute é a aplicabilidade, no contexto do cenário econômico internacional, de práticas protecionistas extremistas que privilegiam indústrias, principalmente por conta de vantagens comparativas artificiais, as quais não são facilmente imitáveis e denotam a aplicação intensiva de capital e subsídios industriais por parte dos Estados.

Não obstante, ações intervencionistas de ordens diversas foram realizadas em todos os países industrializados: criação de fundos de investimento e capital de risco; fomento à consecução de parcerias privadas; isenções e incentivos fiscais; 
dedução para treinamento de pessoal; deferimento de impostos; regras especiais de depreciação, entre outros. Para Peter Evans (2004), o envolvimento do Estado faz parte das regras do jogo em todos esses países.

\section{QUADRO 1}

Tipos de intervenções governamentais

\begin{tabular}{|c|c|c|}
\hline Racionalidade & Principais instrumentos & Países \\
\hline Proteção à indústria infante & $\begin{array}{l}\text { 1. Restrição à importação } \\
\text { e ao investimento } \\
\text { estrangeiro. }\end{array}$ & $\begin{array}{l}\text { Coreia do Sul, Brasil, } \\
\text { Índia }\end{array}$ \\
\hline Geração de Spillovers & $\begin{array}{l}\text { 1. Restrição ao } \\
\text { investimento } \\
\text { estrangeiro. } \\
\text { 2. Política tecnológica. } \\
\text { 3. Investimento em } \\
\text { infraestrutura de } \\
\text { telecomunicações. }\end{array}$ & $\begin{array}{l}\text { Coreia do Sul, Brasil, } \\
\text { Índia } \\
\text { Coreia do Sul, Taiwan } \\
\text { Coreia do Sul, Taiwan }\end{array}$ \\
\hline $\begin{array}{l}\text { Intimidação de competidores } \\
\text { estrangeiros }\end{array}$ & $\begin{array}{l}\text { 1. Subsídios. } \\
\text { 2. Políticas antitrust. }\end{array}$ & $\begin{array}{l}\text { Todos os países } \\
\text { Coreia do Sul }\end{array}$ \\
\hline
\end{tabular}

Fonte: Mody (1989, p. 51).

Historicamente, diversos países incorreram em intervenções na indústria de TI e não se trata de privilégio apenas daqueles que realizaram catch up recentemente ou ainda estão na corrida de emparelhamento, como Brasil e Índia, pois, nos países desenvolvidos, as intervençôes estatais também fizeram parte dos planos de desenvolvimento da indústria. A diferença está nos mecanismos adotados e no período histórico em que essas intervençôes foram efetuadas. A Coreia representa um caso de superação, uma vez que praticamente não existia vantagem comparativa vinculada ao setor de TI (AMSDEN, 1989, p. 82), e o Estado agiu como um empreendedor (AMSDEN, 1989; EVANS, 2004). No caso do Japão, o MITI desempenhou papel fundamental para a política industrial (OZAKI, 1984) e, especificamente, em se tratando da indústria de TI, "ao mesmo tempo que limitava a competição estrangeira e assegurava o acesso à tecnologia, o MITI estava também trabalhando no desenvolvimento da demanda" (EVANS, 2004, p. 141) e utilizando o poder de compra do estado. O despontar japonês culminou ainda com o declínio britânico na indústria de TI, que havia adotado a política do campeão nacional com a ICL (Internatinal Computers Limited). Outra característica básica do caso britânico foi a vinculação com a defesa nacional, o que também não foi suficiente para sustentar 
o setor (EVANS, 2004). Diferenças ainda são encontradas, pois “o Japão partiu de uma base superior de recursos industriais, operando com um mercado doméstico muito maior que o Brasil, a Índia ou a Coréia. O Japão também começou mais cedo" (EVANS, 2004, p. 143). Além do Japão, outros Estados desenvolvidos estiverem também envolvidos com o desenvolvimento do setor de TI, como o projeto Espirit, na Europa, e o Sematech, nos EUA (EVANS, 2004, p.136).

Logo, o argumento neoliberal para a indústria de TI propagado pelas economias desenvolvidas remete ao que Chang (2004) denomina de "chutar a escada" (expressão resgatada de List (1983, p.249), ou seja, uma vez que os países desenvolvidos chegaram ao topo, tenta-se destruir o caminho que fora anteriormente trilhado, o que não pode ser facilmente aceito por conta de algumas justificativas.

Tratando-se da intervenção estatal no setor de TI, tais justificativas podem ser edificadas segundo duas correntes de pensamento: a primeira privilegia uma ação finalística da indústria como própria propulsora de desenvolvimento econômico, constituindo um indutor primário; e a segunda coloca a indústria de TI numa condição intermediária, por servir de insumo industrial tecnológico para setores afins, representando um bem de produção.

Tomando-se a primeira vertente, é possível encontrar alguns indícios que denotam a possibilidade de constatação empírica desta hipótese. Um bom exemplo é o caso da Coreia do Sul. Uma economia periférica, cujo rumo na divisão internacional do trabalho sofreu modificações, tendo a indústria de TI se revelado como um importante precursor das mudanças (EVANS, 2004; GOLDENSTEIN, 1994; KIM, 2005).

Especificamente sobre a indústria de software, encontram-se resultados destacáveis em economias não-centrais, como Índia, Israel e Irlanda (HEEKS; NICHOLSON, 2003). Os desafios para o reposicionamento da indústria de software logicamente não são poucos, nem tão simples. Entretanto, como Peter Evans (2004) destaca, não é conveniente ficar estático na divisão internacional do trabalho e auferir apenas aqueles benefícios ligados diretamente às vantagens comparativas já existentes. A teoria das vantagens comparativas desconsidera em sua estrutura a possibilidade de construção de capacitações, tanto as evolutivas quanto aquelas totalmente inovadoras, que podem permitir que a força produtiva local dispute mercados outrora inacessíveis no cenário da divisão internacional do trabalho, os quais poderiam proporcionar um crescimento mais significativo (PREBISCH, 2000).

Além disso, ao se tomar como referência a noção de fluxo circular da vida econômica proposta por Schumpeter (1982, p 31), a aceitação do argumento das 
vantagens comparativas remeteria os países para uma condição em que haveria a existência de um sistema de valores com uma notável estabilidade, sem produção de excedente, nem desenvolvimento. Entretanto, como o próprio Schumpeter (1982, p. 46) observa, o processo de troca entre trabalho e terra, de um lado, e de bens de consumo, de outro, não são os únicos cursos da vida econômica e as mudanças não podem ser compreendidas por nenhuma análise do fluxo circular. $\mathrm{O}$ fenômeno fundamental do desenvolvimento econômico é a inovação que também é endógena ao sistema capitalista (SCHUMPETER, 1982, p. 48-49).

Uma postura passiva diante das economias centrais remeteria uma economia periférica a uma condição permanente de estagnação e dependência tecnológica e econômica. Alcançar novas posições na divisão internacional do trabalho requer um conjunto de esforços articulados e focalizados em questôes de ordens diversas, que, no contexto deste trabalho, entende-se que sejam capitaneados pelo Estado.

$\mathrm{Na}$ segunda vertente de análise, considerando a condição de bem intermediário, admite-se também o papel de transversalidade do software que possui aplicações nas mais diversas áreas de conhecimento e, por conseguinte, exerce uma influência significativa no dinamismo das economias modernas (CASTELLS, 2003). O software é parte integrante do paradigma da microeletrônica, segmento das TIC, que se disseminou na forma de soluçôes muitas vezes imperceptíveis em grande parte dos hardwares comercializados, conferindo-lhe uma elevada convergência a outros setores industriais.

Devido à sua característica de transversalidade, as contribuições da microeletrônica, mais especificamente a TI, podem ser classificadas como inovações de propriedades revolucionárias que não apenas providenciam a base tecnológica para o surgimento de novos setores, como também afetam diversos outros já existentes (FREEMAN, 1984; FREEMAN; SOETE, 1997; McFARLAN, 1998).

Castells (2003, p. 68) ainda observa que as TIC promoveram uma verdadeira revolução industrial em todas as esferas da sociedade. $\mathrm{O}$ processo atual de difusão da TI constitui uma nova revolução devido à penetração em todos os domínios da atividade humana. Para o autor, "A tecnologia da informação é para esta revolução o que as novas fontes de energia foram para as revoluçōes industriais".

As TIC foram preponderantes para a consolidação do capitalismo moderno por sustentar a aceleração do fluxo de produção e a comunicação. Entende-se que a importância das TIC evidencia-se à medida que se torna possível implementar uma gama variada de tecnologias de forma a contornar a crise de controle proveniente 
da última revolução industrial. A TI seria a etapa mais recente do desenvolvimento contínuo da revolução do controle (CHANDLER, 1990; KUMAR, 1997).

Os efeitos da convergência tecnológica sobre a indústria de software se traduzem numa virtude devido à possibilidade de articulação intersetorial, o que também representa um bom sinal para países em desenvolvimento. Fomenta-se, dessa forma, tanto o desenvolvimento de indústrias diversas, como o próprio setor de software, por meio da utilização de demanda local. É possível argumentar que a indução primária de desenvolvimento e a posição do software como bem de produção encontram repouso nas ideias do paradigma técnico-econômico dominante. Carlota Perez (1989) destaca que haveria uma fase no processo de mudança de paradigmas, na qual o novo e o velho coexistiriam. Isso representaria uma oportunidade singular para países em desenvolvimento em termos de acesso integral à competitividade.

Os Estados procuram acompanhar as tendências dos paradigmas em ascensão, como forma de não tornarem suas indústrias defasadas tecnologicamente (PEREZ, 1989; GILPIN, 1987). A proposta de se engajar num novo padrão de tecnologia poderia se transformar numa via de desenvolvimento, à medida que se obtenha uma inserção com características inovadoras, caso contrário, ficaria a nação destinada a ser mera consumidora de tecnologia, sofrendo as mazelas decorrentes da aprendizagem e adaptação ao novo paradigma.

Essas mazelas podem ser constatadas, por exemplo, analisando-se o fluxo de receitas e despesas de royalties decorrentes das licenças de software entre economias desenvolvidas e subdesenvolvidas. Ao se analisar a balança de receitas e despesas dos royalties entre os EUA e alguns países subdesenvolvidos, percebe-se algo bastante desfavorável: enquanto países latino-americanos e sul-africanos despenderam juntos US\$ 226 milhões, receberam apenas dos EUA menos de 5,5 milhōes em 2003. Os valores despendidos em royalties provenientes do uso de software nesses países são os mais significativos, superando os gastos com Trademarks (US\$111 milhôes), Franchise (US\$ 97 milhōes) e processos industriais (US\$ 89 milhōes) (KONCZ, J.; MANN, M.; NEPHEW, s/d, p.49-50).

Peter Evans (2004, p.35) também destaca que "os Estados com aspirações à transformação estão, quase que por definição, procurando maneiras de participar de setores líderes e descartam aqueles em declínio". Os Estados desejam estar o mais próximo possível da fase inovadora de produtos de maior valor adicionado, impedindo a ocorrência de mazelas como as citadas, promovendo, assim, uma conspiração multidimensional a favor do desenvolvimento. 
Na perspectiva social, ${ }^{1}$

dado o seu crescimento e a intensidade da pesquisa, a informática, amplamente definida, é o mais importante gerador mundial de bons empregos em todo o mundo para aqueles com treinamento técnico. A sua ausência estimula a evasão de cérebros. Expandir a indístria é uma das melhores estratégias para ampliar o emprego de técnicos. Para os paises que consideram a falta de "uma classe média moderna" como central para os seus problemas sociais e politicos, a informática tem um feitiço que vai além do econômico (EVANS, 2004, p.137).

O setor de software trata-se, portanto, de uma oportunidade singular para a promoção de uma conspiração desenvolvimentista, pois possui características que permitiriam as economias periféricas transformarem as posições ocupadas na divisão internacional do trabalho.

Para avaliar essa possibilidade, é conveniente retornar a discussão ao contraargumento da teoria das vantagens comparativas. Será que, mesmo naqueles países subdesenvolvidos, a indústria de software apresentaria características desejáveis para sustentar um esforço desenvolvimentista? A resposta que se dará na seção 4 deste artigo não se consubstanciará sobre as formas de intervenção do Estado e tampouco sobre as escolhas dos papéis necessários ao Estado para realizar a composição conspiratória ou de sua "boa vontade" para a indústria. Pretende-se mostrar que essa indústria, independente de sua localização geográfica, apresenta características que, no mínimo, justificam a escrita destas linhas como suposiçōes de aspirações desenvolvimentistas.

Além disso, quais as características desejáveis do setor de software que poderiam ser capazes de sustentar uma conspiração desenvolvimentista multidimensional e que contemplem em sua estrutura aspectos econômicos, sociais e políticos? Para responder esta questão, lança-se mão de algumas singularidades concomitantes: além da convergência tecnológica, conforme explicado nesta seção, consideram-se

1 É relevante destacar que não existe uma vinculação automática entre o desenvolvimento da indústria de software e o desenvolvimento social em países subdesenvolvidos, em decorrência de alguns problemas do setor vinculados tanto à oferta quanto à demanda. No caso da oferta, por exemplo, não é fácil acumular capacitações tecnológicas no contexto de países em desenvolvimento cujas dificuldades se encontram na complexidade e na fragilidade dos processos de aprendizagem (ROUSSEVA, 2006), o que dificulta o desenvolvimento do setor nesses países. Por outro lado, conforme observado por Veiga (2008), existem problemas relacionados à demanda, como, por exemplo, os de ordem educacional, que implicam barreiras para a inclusão digital e a consequente limitação de difusão de software. Em ambos os casos, a ação de políticas complementares é essencial aos intentos de desenvolvimento do setor de software. 
também importantes a elevada intensidade tecnológica, a adição de valor e os benefícios sociais gerados na indústria..

Essas singularidades, juntamente com outros argumentos apresentados nesta seção, tornam-se essenciais para o esfacelamento da inércia desenvolvimentista no setor. $\mathrm{Na}$ seção 4, tais singularidades serão avaliadas como forma de, mais uma vez, se perceber a capacidade da indústria de software em sustentar a tese principal proposta neste trabalho.

\section{Contraponto ao argumento da desejabilidade da indústria de alto valor adicionado}

Na obra de Paul Krugman e Maurice Obstfeld (1999), identificam-se dois argumentos que contestam a ideia de uma "conspiração multidimensional" em torno de setores de alta intensidade tecnológica. Tais formulações podem ser anunciadas da seguinte forma: $\mathrm{i}$ - o argumento sobre a desejabilidade da indústria de alto valor adicionado não seria suficiente para promover o bem-estar social e tampouco o bastante para determinar um elevado valor adicionado por trabalhador; ii - a inevitabilidade dos supostos da teoria das vantagens comparativas, como determinantes das desigualdades de desenvolvimento por conta do desequilíbrio das condiçôes dos fatores industriais, impediria a captura de benefícios provenientes desse tipo de indústria.

Krugman e Obstfeld (1999, p. 283) questionam sobre o interesse em investimentos nas indústrias de alto valor adicionado, argumentando que

os economistas são muito céticos a respeito dessa idéia. Se as indístrias com alto valor adicionado são tão desejáveis, eles perguntam, por que os recursos não se movem para elas sem qualquer estímulo do governo? A principal resposta que os economistas sugerem é que as induistrias com alto valor adicionado por trabalhador são tipicamente muito capital-intensivas, isto é, elas têm baixo valor agregado por unidade de capital. E desde que o capital é um recurso tão escasso quanto o trabalho, isto significa que não há garantias de que a promoção das indústrias com alto valor adicionado por trabalhador aumentará a renda nacional.

A resposta a essa formulação teórica tem respaldo na análise de dados empíricos da adição de valor sobre o trabalho de algumas indústrias americanas, em 1991 (química, têxtil, petróleo, automobilística, entre outras). Os autores observam que, a despeito da alta produtividade do trabalho em algumas indústrias, o fator 
preponderante do retorno dos investimentos é a intensidade do capital investido. Tanto naquelas indústrias onde se verifica alta produtividade do trabalho - como o caso do petróleo - quanto em outras que não possuem um valor adicionado por trabalhador tão elevado - como a automobilística - a intensidade do capital é elemento presente e incontestável. Isso possuiria duas implicaçôes: o alto valor adicionado por trabalhador é função da intensidade de capital investido; e o alto valor adicionado por trabalhador não é algo suficientemente seguro para decidir sobre o investimento da indústria.

$\mathrm{O}$ argumento de Krugman e Obstfeld acaba sendo reforçado, de certa forma, pela teoria das vantagens comparativas, naquilo que se denomina de custos de oportunidade, conceito que possui origem no modelo Ricardiano de vantagens comparativas (RICARDO, 1982). Em sua formulação, fica implícita a necessidade de avaliação dos custos de oportunidade como fator preponderante sobre a escolha da opção de investimento, de forma a maximizar a eficiência alocativa dos fatores de produção.

A avaliação sobre a eficiência alocativa de recursos aconteceria segundo pressupostos estáticos de desenvolvimento, obedecendo a lei de maiores retornos sem admitir a possibilidade de criação de novos fatores por conta da necessidade de aplicação de esforços adicionais. Tais esforços representariam uma perda de produtividade geral dos fatores devido às condiçôes preexistentes no ambiente nacional, as quais não seriam favoráveis para o surgimento de um empreendimento que não estivesse casado aos fatores preexistentes.

Todavia, é importante destacar que o mecanismo de crescimento identificado nas economias centrais não sugere que esse seja um caminho a ser seguido na íntegra por economias periféricas, em decorrência das diversas desigualdades de ordens social, política e econômica. Logo, apesar do hiato em termos de recursos e capacitações, diferenças nas instituições, entre outros, os fatos que se sucederam na história das economias centrais servem de indícios de possíveis vias de crescimento, as quais precisam ser consideradas nas opçōes desenvolvimentistas nacionais. O papel do Estado no fomento das vantagens comparativas é criar condições no mercado, deixando-o tão atrativo que as empresas se sintam encorajadas e o setor se torne desejável demais para ser negligenciado (EVANS, 2004, p. 91).

Na próxima seção, apresentam-se os argumentos favoráveis à intervenção estatal no setor de software. 


\section{A Indústria de software: justificativas para uma conspiração desenvolvimentista multidimensional}

A proposta desta seção é evidenciar que existem características desejáveis no setor de software que o tornam um representante daqueles denominados favoráveis a uma "conspiração desenvolvimentista multidimensional". Logo, o argumento que aqui se apresenta versará sobre a atratividade de interesses privados e as justificativas estatais para a intervenção sobre os aspectos da intensidade tecnológica, a adição de valor e os benefícios sociais gerados na indústria. As características da indústria são trazidas ao debate mediante a análise de resultados no Brasil e nos EUA. A construção distinta de indicadores sobre as indústrias selecionadas nestes países se deu de forma a isolar a ocorrência do efeito país na indústria e verificar as limitaçôes ou ratificações decorrentes da teoria das vantagens comparativas sobre a adição de valor e os benefícios sociais. Dessa forma, será possível perceber indícios de que as mazelas ou proficiência da indústria são realmente inerentes ao setor, ou decorrentes das vantagens comparativas. Não se pretende com isso criar comparações excludentes entre as especificidades das indústrias em cada país e tampouco avaliar qual delas gera os melhores resultados ou é mais competitiva; pelo contrário, propōe-se uma articulação complementar entre os resultados da indústria de software nos dois países como forma de contribuir com a sustentação do argumento principal deste trabalho.

\subsection{Um setor de alta intensidade tecnológica}

Uma forma de se calcular a intensidade tecnológica de uma indústria é tomar o valor de investimento total em P\&D e dividi-lo pelo valor total da produção da indústria ou a receita líquida, ou ainda avaliar a quantidade de patentes auferidas pelo setor. Assim, a importância dos gastos em P\&D e a quantidade de patentes se verifica à medida que estes representam os esforços da empresa para geração de inovaçôes tecnologias.

Apesar da existência de bias $^{2}$ na utilização dos indicadores de inovação, Pavitt $(1985$, p. 82) assume que o uso dessas estatísticas pode ser direcionado para avaliação

2 É importante ressaltar que o setor de software apresenta segmentos diferençados pela adição de valor, conforme observado por Roselino (2006). Essa característica pode implicar intensidade tecnológica variada de acordo com cada segmento da indústria, tanto por conta da dimensão do faturamento líquido quanto pela variação tecnológica entre firmas que determina a medição de esforços de P\&D com desvios, de acordo com Pavitt (1985). Assim, admite-se a possibilidade de existência de bias na utilização de indicadores de intensidade tecnológica para a indústria de software. Porém, adota-se este indicador devido à mesma justificativa dada por Pavitt (1985, p.82), que é a "considerably difficulty of collecting comprehensive and complete data on the inputs and the outputs of innovative activities". 
de desenvolvimento dos campos tecnológicos e análise de políticas desenvolvimentistas, provendo subsídios para análise da intensidade tecnológica de setores industriais.

Nessa linha, o último resultado da Pintec (IBGE, 2007) apresenta informaçôes que corroboram a ideia da representatividade do setor de software em termos de inovação. Três indicadores despertam a atenção nessa pesquisa: a taxa de inovação e os percentuais de incidência dos dispêndios em atividade inovativas e em P\&D sobre a receita líquida (Tabela 1). Se tomarmos a comparação dos valores de dispêndio em P\&D na indústria americana, a tendência é análoga. Verifica-se a indústria de software na segunda posição da tabela com esforços bem significativos (Tabela 2).

TABELA 1

Taxas de inovação e incidência sobre a receita líquida de venda dos dispêndios realizados em atividades inovativas e internas de $P \& D$, segundo atividades selecionadas da indústria e dos serviços Brasil - 2005

\begin{tabular}{|c|c|c|c|c|}
\hline \multirow{3}{*}{$\begin{array}{l}\text { Atividades selecionadas } \\
\text { da indústria e dos serviços }\end{array}$} & \multirow{3}{*}{$\begin{array}{l}\text { Intensidade } \\
\text { tecnológica }\end{array}$} & \multirow{3}{*}{$\begin{array}{l}\text { Taxa de } \\
\text { inovação }\end{array}$} & \multicolumn{2}{|r|}{ Em porcentager } \\
\hline & & & $\begin{array}{l}\text { Incidência } \\
\text { líquida o } \\
\text { dispêndio }\end{array}$ & $\begin{array}{l}\text { bre a receita } \\
\text { vendas dos } \\
\text { ealizados nas }\end{array}$ \\
\hline & & & $\begin{array}{l}\text { Atividades } \\
\text { inovativas }\end{array}$ & $\begin{array}{l}\text { Atividades } \\
\text { internas de } \\
\text { P\&D }\end{array}$ \\
\hline Pesquisa e desenvolvimento & Não informada & 97,6 & 68,9 & 63,07 \\
\hline Consultoria em software & Alta & 77,9 & 5,5 & 2,74 \\
\hline Automobilística & Média-alta & 71,1 & 5,6 & 1,84 \\
\hline $\begin{array}{l}\text { Máquinas para escrit. e } \\
\text { equip. de informática }\end{array}$ & Alta & 69,2 & 3,8 & 1,48 \\
\hline $\begin{array}{l}\text { Instrum. méd. hospitalar, } \\
\text { ópticos e outros }\end{array}$ & Média-alta & 68,0 & 5,3 & 2,26 \\
\hline Refino de petróleo & Média-baixa & 62,4 & 1,4 & 0,83 \\
\hline Material eletrônico básico & Alta & 58,7 & 2,7 & 0,86 \\
\hline $\begin{array}{l}\text { Aparelho e equip. de } \\
\text { comunicações }\end{array}$ & Alta & 55,2 & 5,5 & 1,12 \\
\hline Farmacêutica & Alta & 52,4 & 4,2 & 0,72 \\
\hline Celulose e outras pastas & Média-Baixa & 51,7 & 5,1 & 0,38 \\
\hline Têxtil & Baixa & 33,3 & 2,9 & 0,22 \\
\hline
\end{tabular}

Fonte: IBGE (2006a).

Nota: A taxa de inovação é calculada através da razão entre a quantidade de empresas que inovaram em produto e processo e a quantidade total de empresas da amostra (IBGE, 2007a). A intensidade tecnológica para o setor de software foi deduzida a partir da definição da OECD para setores de alta intensidade tecnológica (HATZICHRONOGLOU, 1997). 
TABELA 2

P\&D e vendas líquidas, segundo setores industriais selecionados Estados Unidos - 1991-2003

\begin{tabular}{|c|c|c|c|c|}
\hline Setores & $\begin{array}{l}\text { P\&D Total } \\
\text { (US\$ } \\
\text { millions) }\end{array}$ & $\begin{array}{l}\text { Venda } \\
\text { líquidas } \\
\text { (US \$ } \\
\text { millions) }\end{array}$ & $\begin{array}{l}\text { Intensi- } \\
\text { dade P\&D } \\
(\%)\end{array}$ & $\begin{array}{c}\text { Intensidade } \\
\text { tecnológica } \\
\text { (1) }\end{array}$ \\
\hline R\&D services (2003) & 19497 & 108886 & 17,9 & n.i. \\
\hline $\begin{array}{l}\text { Software and Computer- } \\
\text { related services (2003) }\end{array}$ & 27436 & 201567 & 13,6 & Alta \\
\hline Pharmaceuticals (1991-1997) & n.i. & n.i. & 12.4 & Alta \\
\hline $\begin{array}{l}\text { Computer/electronic products } \\
\text { (2003) }\end{array}$ & 39871 & 450528 & 8,8 & Alta \\
\hline Aerospace/defense (2003) & 23410 & 270054 & 8,7 & Alta \\
\hline $\begin{array}{l}\text { Radio, television, and comm.. } \\
\text { equipment (1991-1997) }\end{array}$ & n.i. & n.i. & 8.6 & Alta \\
\hline $\begin{array}{l}\text { Medical, precision, and optical } \\
\text { instruments (1991-1997) }\end{array}$ & n.i. & n.i. & 7.9 & Alta \\
\hline Chemicals (2003) & 32474 & 489604 & 6,6 & Média- Alta \\
\hline $\begin{array}{l}\text { Electrical machinery and } \\
\text { apparatus (1991-1997) }\end{array}$ & n.i. & n.i. & 4.1 & Média - Alta \\
\hline Automotive (2003) & 16874 & 703834 & 2,4 & Média - Alta \\
\hline $\begin{array}{l}\text { Refined petroleum products } \\
\text { (1991-1997) }\end{array}$ & n.i. & n.i. & 1.3 & Média - Baixa \\
\hline $\begin{array}{l}\text { Wood, paper, paper, printing, } \\
\text { publishing (1991-1997) }\end{array}$ & n.i. & n.i. & 0,5 & Baixa \\
\hline Textiles (1991-1997) & n.i. & n.i. & 0.2 & Baixa \\
\hline
\end{tabular}

Fonte: NSF - National Science Foundation (2007, p. 4-17)

(1) Obtido de Hatzichronoglou (1997, p. 6)

n.i. - não informado.

Nos EUA, especificamente, a Microsoft foi a empresa que mais investiu em P\&D em 2003 (US\$ 7.779 milhões), com uma intensidade de 21,1\% (NSF, 2007, p. 4-20).

Ressaltando que esses valores acompanham tendência internacional da indústria de software (OECD, 2007), como poderíamos explicar esses resultados? De acordo com Gaio (1990), software é uma parte intrínseca e penetrante do paradigma de TI que tem características estranhas e complexas. Primeiro, software é um elemento nuclear da TI por implementar as características fundamentais de sistemas baseados em microeletrônica, que possuem a capacidade para executar uma gama extensiva de 
funçōes. Segundo, software é uma ferramenta que gera um produto intangível, cujo valor pode ser determinado pela capacidade efetiva das operaçôes computacionais que são empreendidas e pela segurança da representação dos domínios da aplicação que é modelada, seguindo critérios estabelecidos pelos usuários. Em síntese, a construção de um software representa a incorporação do conhecimento em produtos e sistemas de produção, que essencialmente se dá por meio de um processo de análise (pesquisa), seguido pela implementação (desenvolvimento).

A velocidade na qual as inovações são introduzidas e transformadas em produtos novos e sua rápida obsolescência são os destaques desta indústria que se mostra muito dinâmica. Podem, ainda, ser destacadas algumas características básicas: “[...] a alta velocidade de introdução de inovaçôes técnicas e no desenvolvimento de produtos, novos ou existentes; a competição acirrada; o baixo investimento em capital fixo; e a capacidade criativa e intelectual da mão-de-obra, que é o seu grande ativo" (BRANCO; MELO, 2003, p. 2).

Uma primeira inferência possível pelo cruzamento dessas definições com os resultados das Tabelas 1 e 2 é que a indústria de software compreende um setor de alta intensidade tecnológica. A característica comum de setores desse tipo é a aplicação intensiva de ciência e tecnologia avançadas, pelo que se define de setores de "alta tecnologia", cuja expressão refere-se a um processo de produção em que o conhecimento e a informação constituem o insumo principal (CASTELLS, 2003).

Em relação às patentes, ${ }^{3}$ a análise dos dados do escritório americano reserva algo ainda mais significativo para a indústria de software. Computadas todas as patentes auferidas na agência americana até 2006, a IBM lidera o ranking com o total de 45.179, seguida pela Canon (33.110), Hitachi (27.988), Toshiba (26.035) e GE (25.734). Até a vigésima posição dessa lista, ainda são mencionadas empresas como a Matsushita, a Sony, a Nec, a Motorola, a Fujitsu, a Samsung, a Siemens, a Fuji, a Xérox, a Texas, a Intel, todas conhecidas como empregadoras intensivas de microeletrônica (e consequentemente software) em produtos e processos (USPTO, 2007).

3 Embora Bessen e Hunt (2004, p.4) tenham observado que "most software patents are assigned to manufacturing firms and relatively few are actually assigned to firms in the software publishing industry", esse dado serve justamente para ratificar a hipótese da importância da convergência tecnológica para a indústria de software. Ou seja, embora as patentes tenham sido auferidas por empresas que não possuem atividades econômicas principais no setor de software, esse dado ratifica a posição do software como insumo tecnológico de produção, o que realça sua desejabilidade sob a perspectiva de desenvolvimento industrial, que é a tese principal deste trabalho. Dado que as empresas tendem a se concentrar em seu core competence, tem-se a possibilidade de se destinar à indústria de software demandas específicas enquanto bem de produção, na forma de software embarcado. É importante ainda observar que, devido à heterogeneidade e à consequente complexidade de proteção intelectual na indústria, tem-se a necessidade de instrumentos de proteção intelectual diferenciados, conforme discutido por Carneiro (2007) 
O que a intensidade tecnológica deixa como lição para uma intervenção estatal? A resposta caminha em duas direçôes, além das mencionadas na seção 2: o potencial de deslocamento na divisão internacional do trabalho; e os requisitos necessários aos esforços inovativos. A indústria de software carrega em sua estrutura a propensão natural para a inovação e, logicamente, a questão remete para quem sairá na frente num determinado segmento ou quem conseguirá promover uma distinção significativa de seus produtos por conta da inovação. Com isso, e admitindo-se o gap e o tempo de aprendizado de outras nações que tenderiam a formular estratégias imitativas, ter-se-ia um distanciamento que promoveria uma vantagem sustentável.

$\mathrm{Na}$ segunda linha, e também concebendo a possibilidade de modificação na divisão internacional do trabalho, observa-se que as estratégias baseadas em inovação são a fonte de vantagens competitivas predominantes nos setores de alta intensidade tecnológica. As empresas mais competitivas que atuam nesses setores necessitam empreender grandes esforços em $\mathrm{P} \& \mathrm{D}$, realizando investimentos de ordem física e humana, que não necessariamente se traduzem em retornos significativos. Também se torna necessário o estabelecimento do aprendizado tecnológico, que requer a implantação de mecanismos de interação e de difusão tecnológica, que possibilitem aumento de mobilidade na adoção e geração de inovações.

Portanto, aspectos relacionados à eficiência do sistema educacional, à existência de empresas inovadoras, à presença de infraestrutura tecnológica de apoio, a todos aqueles fatores que compreendem o sistema nacional de inovação e ao Estado, enfim, são essenciais para adoção da estratégia de inovação. Dadas as características da intensidade tecnológica do setor, ter-se-ia, além das justificativas estatais, uma justificativa empresarial devido à maior lucratividade por conta da possibilidade de inovação. Isso representa uma condição oportuna em favor de uma articulação para o desenvolvimento do setor.

\subsection{Adição de valor e benefícios sociais na indústria de software: limitações da tese de Krugman e Obstfeld}

Esta seção reúne evidências que delimitam a abrangência da tese de Krugman e Obstfeld (1999), reforçando a proposição de Evans (2004). Primeiro, é conveniente inserir na análise originalmente formulada por Krugman e Obstfeld, para efeito de comparação, os resultados provenientes da indústria de software, uma indústria prioritariamente intensiva em trabalho (GAIO, 1990; BRANCO; MELO, 2003, p. 2). 
Para a avaliação dos argumentos dispostos neste trabalho, foram elaboradas as tabelas 3 e 4, que contêm indicadores sobre atividades industriais nos EUA e Brasil, respectivamente.

TABELA 3

Adição de valor nas indústrias, segundo setores Estados Unidos - 1991- 2005

\begin{tabular}{|c|c|c|c|c|c|c|}
\hline \multirow[b]{2}{*}{ Indústrias } & \multicolumn{6}{|c|}{1991} \\
\hline & $\begin{array}{c}\text { Quantidade } \\
\text { de traba- } \\
\text { Ihadores } \\
\text { em tempo } \\
\text { parcial e } \\
\text { integral } \\
\text { (mil)s }\end{array}$ & $\begin{array}{l}\text { Gastos de } \\
\text { produção } \\
\text { (em } \\
\text { produtos } \\
\text { e } \\
\text { serviços) } \\
\text { (US\$ bi) } \\
\end{array}$ & $\begin{array}{c}\text { Valor } \\
\text { adicionado } \\
\text { (vendas } \\
\text { - gastos) } \\
\text { (US\$ bi) }\end{array}$ & $\begin{array}{l}\text { VA/qt } \\
\text { trabalha- } \\
\text { dores } \\
\text { (US\$) }\end{array}$ & $\begin{array}{l}\text { VA/ } \\
\text { gastos de } \\
\text { produção }\end{array}$ & $\begin{array}{c}\text { Gastos de } \\
\text { produção/ } \\
\text { qt traba- } \\
\text { lhadores } \\
\text { (US\$) }\end{array}$ \\
\hline Têxtil & 689 & 48,2 & 23,1 & $33.526,9$ & 0,479253 & $69.956,5$ \\
\hline Produtos elétricos & 572 & 39,2 & 36,7 & $64.160,8$ & 0,936224 & $68.531,5$ \\
\hline Química & 996 & 199,8 & 106,5 & $106.928,0$ & 0,533033 & $200.602,0$ \\
\hline Automobilística & 1.048 & 183,2 & 56,7 & $54.103,1$ & 0,309498 & $174.809,0$ \\
\hline Petróleo e carvão & 155 & 131,2 & 243 & $1.567 .742,0$ & 1,852134 & $846.452,0$ \\
\hline $\begin{array}{l}\text { Sistemas de } \\
\text { computadores e } \\
\text { serviços correlatos }\end{array}$ & 485 & 6,3 & 34 & $70.103,1$ & 5,396825 & $12.989,7$ \\
\hline $\begin{array}{l}\text { Alimentos, bebidas e } \\
\text { tabaco }\end{array}$ & 1.715 & 315,3 & 116,3 & $67.813,4$ & 0,368855 & $183.848,0$ \\
\hline TIC & 3.418 & 224,0 & 204,2 & $59.742,5$ & 0,911607 & $65.535,4$ \\
\hline \multirow[b]{2}{*}{ Indústrias } & \multicolumn{6}{|c|}{2005} \\
\hline & $\begin{array}{l}\text { Quantidade } \\
\text { de traba- } \\
\text { Ihadores } \\
\text { em tempo } \\
\text { parcial e } \\
\text { integral } \\
\text { (mil) }\end{array}$ & $\begin{array}{c}\begin{array}{c}\text { Gastos } \\
\text { de }\end{array} \\
\text { produção } \\
\text { (em } \\
\text { produtos } \\
\text { e } \\
\text { serviços) } \\
\text { (US\$ bi) } \\
\end{array}$ & $\begin{array}{c}\text { Valor } \\
\text { adicionado } \\
\text { (vendas } \\
\text { - Gastos) } \\
\text { (US\$ bi) }\end{array}$ & $\begin{array}{l}\text { VA/qt } \\
\text { trabalha- } \\
\text { dores } \\
\text { (US\$) }\end{array}$ & $\begin{array}{l}\text { VA/ } \\
\text { gastos de } \\
\text { produção }\end{array}$ & $\begin{array}{c}\text { Gastos de } \\
\text { produção/ } \\
\text { qt traba- } \\
\text { lhadores } \\
\text { (US\$) }\end{array}$ \\
\hline Têxtil & 389 & 44,7 & 24 & $61.696,7$ & 0,536913 & $114.910,0$ \\
\hline Produtos elétricos & 436 & 61,4 & 47,5 & $108.945,0$ & 0,773616 & $140.825,7$ \\
\hline Química & 876 & 330,0 & 180,5 & $206.050,2$ & 0,546970 & $376.712,3$ \\
\hline Automobilística & 1.100 & 387,5 & 125,1 & $113.727,3$ & 0,322839 & $352.272,7$ \\
\hline Petróleo e carvão & 111 & 334,1 & 30,0 & $270.270,3$ & 0,089793 & $3.009 .910,0$ \\
\hline $\begin{array}{l}\text { Sistemas de } \\
\text { computadores e } \\
\text { serviços correlatos }\end{array}$ & 1201 & 39,7 & 148,1 & $123.313,9$ & 3,730479 & $33.055,8$ \\
\hline $\begin{array}{l}\text { Alimentos, bebidas e } \\
\text { tabaco }\end{array}$ & 1.687 & 483,1 & 175,7 & $104.149,4$ & 0,363693 & $286.366,3$ \\
\hline TIC & 3.887 & 461,3 & 653,7 & $168.176,0$ & 1,417082 & $118.677,6$ \\
\hline
\end{tabular}

Fonte: BEA (2007). Elaboração dos autores. 


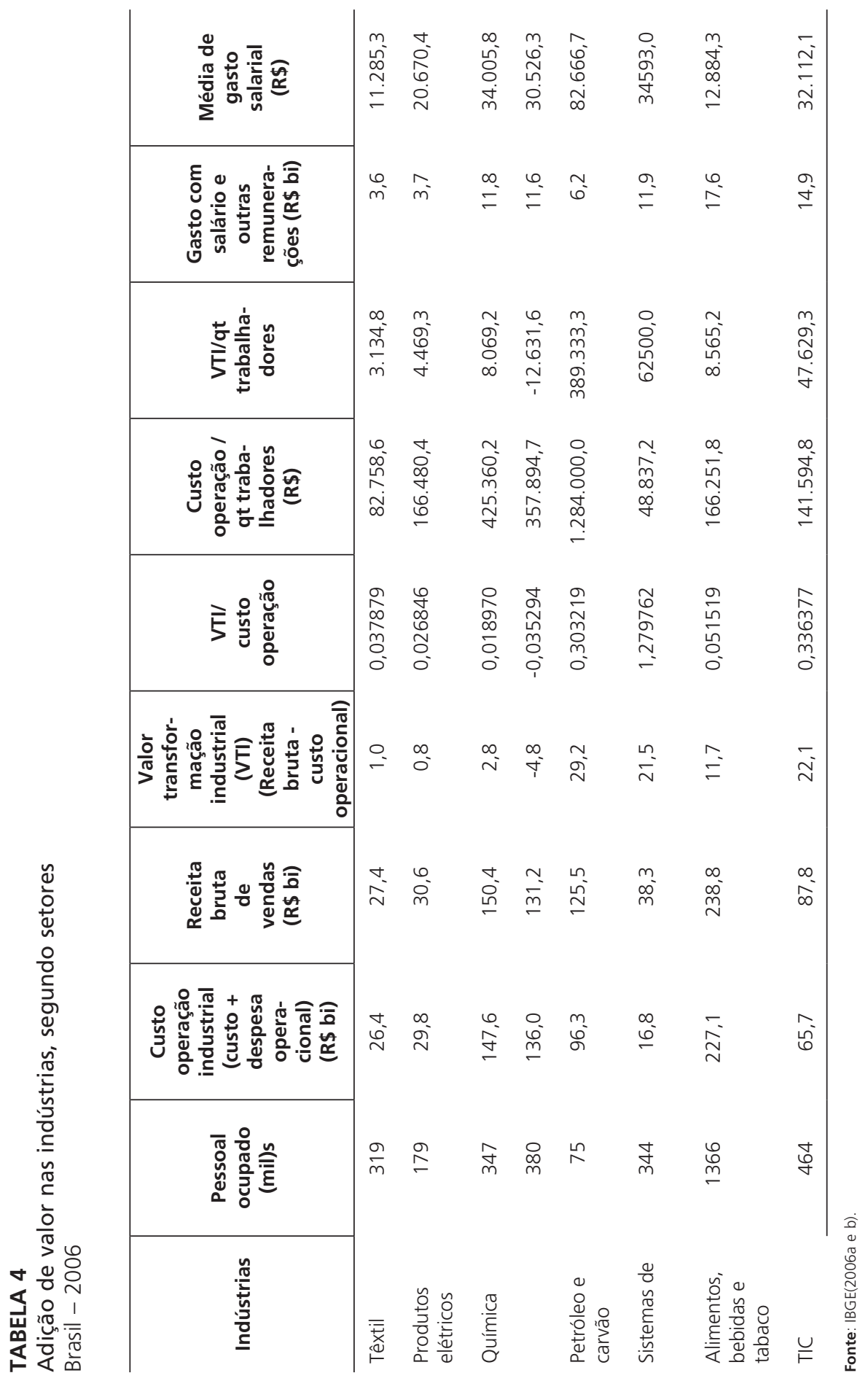

310 Revista Brasileira de Inovação, Rio de Janeiro (RJ), 9 (2), p. 291-322, julho/dezembro 2010 
É importante atentar ao fato de que os títulos dos indicadores são diferenciados. Isso foi feito de forma proposital para que não sejam empreendidas comparações transversais entre as indústrias nos dois países, uma vez que as metodologias e os cálculos são diferenciados por conta das fontes de obtenção dos dados. Entretanto, tais indicadores servem para propósito análogo, de forma a viabilizar a comparação entre indústrias e tendências dentro de um determinado país apenas. Efetuando-se uma comparação linear entre indicadores das indústrias de cada país, é possível perceber características bem interessantes (Quadro 2).

\section{QUADRO 2}

Características comparadas dos indicadores de indústrias selecionadas no Brasil e nos EUA

\begin{tabular}{|l|l|}
\hline \multicolumn{1}{|c|}{ Indicadores } & \multicolumn{1}{|c|}{ Características } \\
\hline $\begin{array}{l}\text { Quantidade de } \\
\text { trabalhadores }\end{array}$ & $\begin{array}{l}\text { Exceto automobilística e software, todos os setores } \\
\text { apresentaram redução dos postos de trabalho nos EUA. } \\
\text { A indústria de software registrou o maior crescimento de } \\
\text { postos de trabalho. }\end{array}$ \\
\hline $\begin{array}{l}\text { Gastos de produção (ou } \\
\text { custo operação) }\end{array}$ & $\begin{array}{l}\text { A indústria de software apresentou o maior crescimento } \\
\text { proporcional dos gastos de produção. }\end{array}$ \\
\hline $\begin{array}{l}\text { Gastos de produção } \\
\text { (ou custo operação)/qt } \\
\text { trabalhadores }\end{array}$ & $\begin{array}{l}\text { A indústria de software é a menos intensiva em capital por } \\
\text { unidade de trabalho. }\end{array}$ \\
\hline $\begin{array}{l}\text { VA (ou VTI)/gastos de } \\
\text { produção (ou custo } \\
\text { operação) }\end{array}$ & $\begin{array}{l}\text { A indústria de software adicionou maior valor por unidade de } \\
\text { capital do que as demais indústrias. }\end{array}$ \\
\hline $\begin{array}{l}\text { VA (ou VTI)/qt } \\
\text { trabalhadores }\end{array}$ & $\begin{array}{l}\text { Mesmo com o aumento significativo dos postos de trabalho, } \\
\text { a indústria de software ainda manteve um nível elevado de } \\
\text { adição de valor por unidade de trabalho, se comparada às } \\
\text { demais indústrias nos EUA. }\end{array}$ \\
\hline
\end{tabular}

Fonte: Elaboração dos autores.

Tomando-se esses indicadores como referência, nota-se ainda que a indústria de petróleo, por exemplo, possui o maior retorno sobre o trabalhador, bem como elevados gastos de produção, se comparada às demais. Isso corroboraria a primeira afirmação de Krugman e Obstfeld (1999), pois se trata de uma indústria intensiva em capital, implicando um elevado valor adicionado por trabalhador, porém com uma taxa de retorno normal (8,9\% em 2005, na indústria americana, e 30,3\% em 2006, no Brasil). Reconhece-se, portanto, neste estudo, a importância dos gastos 
de capital como elemento de influência na produtividade do trabalho. Contudo, se observarmos os dados referentes à indústria de software e serviços correlatos, percebe-se que se trata de uma indústria intensiva em trabalho, pouco intensiva em capital, com elevado valor adicionado por trabalhador, porém possuindo uma taxa de retorno extremamente mais significativa, comparando-se às indústrias nos EUA (370\%). No Brasil, o retorno da indústria de software é também acentuado (128\%) e fica bem acima do valor apresentado pelas demais indústrias brasileiras.

Apesar da diferença dos valores sobre pessoal ocupado, gastos e valor adicionado encontrados no Brasil e nos EUA, é possível inferir sobre a significativa representatividade do valor adicionado na indústria de software em consequência da intensidade de trabalho, se comparada às demais indústrias. A complementação analítica entre os resultados do Brasil e dos EUA é oportuna, uma vez que elimina os efeitos das distâncias econômicas e das condições de desenvolvimento, concluindo que a adição de valor por trabalhador trata-se de um efeito relacionado à indústria e não ao país. Observa-se também que as indústrias química e petroleira americanas sofreram redução dos postos de trabalho entre 1991 e 2005 e aumento dos gastos, mas não tiveram crescimento de retorno tão significativo quanto a indústria de software nesse intervalo. Assim, ocorrem algumas limitações evidentes no argumento de Krugman e Obstfeld (1999), primeiro, devido ao elevado retorno da indústria de software (intensiva em trabalho) e, segundo, porque não há intensidade de capital (como identificado nos setores químico e petroleiro) que justifique a produtividade do trabalho nessa indústria.

Reforçando a ideia de uma conspiração multidimensional em torno da indústria de software, dois aspectos merecem ainda ser mencionados: a venda bruta do setor de TIC (a soma das colunas valor adicionado e gastos de produção das Tabelas 3 e 4); e a qualidade dos postos de trabalho.

A venda bruta do setor de TIC alcançou nos EUA, em 1991, 428 bilhôes de dólares americanos, perdendo por uma pequena diferença apenas para a indústria de alimentos, bebidas e tabaco, que vendeu US\$ 431 bi. Já em 2005, as vendas do setor de TIC nos EUA alcançaram a cifra aproximada de 1 trilhão de dólares americanos, superando qualquer outra indústria naquele ano, dos quais a indústria de software representou aproximadamente $17 \%$. Esse dado reforça o argumento apresentado anteriormente e novamente limita a tese de Krugman e Obstfeld (1999), uma vez que se tem uma contribuição nítida em termos de renda nacional por conta do setor. No Brasil, a receita bruta do setor de TIC não é tão expressiva e isso pode revelar justamente a posição que o país ocupa na divisão internacional do trabalho. 
Em relação à qualidade dos postos de trabalho, pode-se analisar a questão sobre dois aspectos: o gasto e a renda salarial média; e o grau de instrução dos trabalhadores. Quanto ao primeiro, os dados da indústria de software no Brasil revelam que, excetuando a indústria de petróleo $(\mathrm{R} \$$ 82.667), o gasto médio por trabalhador é o maior ( $\mathrm{R} \$ 34.593$ ) entre os setores apresentados na Tabela 4. Analisando-se a Tabela 5, é possível perceber que, nos EUA, a indústria de software (atividades de projeto de software e correlatas - NAICS 541500) apresentou a maior média salarial por trabalhador (US\$ 78 mil). No caso brasileiro, embora a condição não seja das melhores, se comparada às demais indústrias, o resultado não é tão ruim.

\section{TABELA 5}

Média salarial anual por trabalhador Brasil e Estados Unidos - 2007-2008

\begin{tabular}{lcc}
\hline \multicolumn{1}{c|}{ Indústria } & Brasil - 2007 (R\$ mil) & EUA - 2008 (US\$ mil) \\
\hline Química & 38 & 54 \\
Automobilística & 45 & 59 \\
Alimento, bebida e tabaco & 14 & 41 \\
Elétricos & 28 & 42 \\
Petróleo & 102 & 68 \\
Têxtil & 11 & 32 \\
Software & $\mathbf{3 0}$ & $\mathbf{7 8}$ \\
\hline
\end{tabular}

Fonte: MTE (2009); BLS (2009).

Adicionalmente, efetuando-se uma comparação entre o grau de instrução da mão de obra empregada nas indústrias em estudo no Brasil, observa-se que o setor de software apresenta posição bastante destacada. Para todas as classes de atividades industriais relacionadas ao desenvolvimento de software, mais de 60\% da mão de obra empregada está cursando ou já concluiu o ensino superior, contrastando com todas as demais indústrias: petróleo (35\% para refino de petróleo); automóveis (33\%); químicos (aproximadamente 30\% na média); tabaco (26\% para processamento industrial do fumo); produtos elétricos (12,9\%); e têxtil (4\%) (MTE, 2009).

Além disso, as taxas de crescimento de postos de trabalho e da adição de valor no setor de software americano também se mostram como justificativas plausíveis para a execução de esforços de desenvolvimento e atração desse tipo de empreendimento, em detrimento da aceitação dos pressupostos da teoria das vantagens comparativas. A resposta preliminar que se fornece no contexto deste trabalho é que a elevada adição 
de valor na indústria de software provém dos retornos crescentes proporcionados por economias de escala e feedback positivo (SHAPIRO; VARIAN, 1999). A ideia se concentra na cobertura dos custos amortizados (custos da primeira cópia), os quais seriam os mais significativos na cadeia de valor do software e na ocorrência de custos de reprodução demasiadamente inferiores, que proporcionariam economias de escala consideráveis.

Por outro lado, fomentam-se o aprisionamento tecnológico e o feedback positivo por meio das redes de usuários e das externalidades do produto de software, que provocam um distanciamento das empresas líderes, acirrando as posiçôes de mercado e aumentando a lucratividade em médio e longo prazos. A partir desse mecanismo, consegue-se estabelecer na indústria uma posição privilegiada com a garantia de retornos crescentes de capital e distanciamento de concorrentes. A explicação converge para a identificação de uma indústria intensiva em trabalho, com menor intensidade de capital e com elevadas taxas de retorno. Logo, esse argumento constitui uma justificativa contundente para a realização de investimentos no setor e materializa interesses privados para a promoção de desenvolvimento, dentro da chamada conspiração multidimensional, por conta de uma acumulação de capital mais acentuada. Essa explicação pode ser confirmada pela análise dos dados relacionados à adição de valor no segmento de software-produto na indústria brasileira. Tomando-se como referência a receita líquida divida pela quantidade de pessoal ocupado, obtêm-se R\$108.092 per capita (ROSELINO, 2006, p. 163), o que fornece um destaque ainda maior do que o apresentado na Tabela 4 ( $\mathrm{R} \$$ 87.086).

Por fim, a discussão apresentada nesta seção serve para reforçar o papel das TIC no novo paradigma técnico-econômico, no qual se tem uso intensivo de informação, flexibilidade produtiva, intensidade de capital humano, entre outros, conforme observado por Perez (2005). As TIC, ao incorporarem o conhecimento humano na forma de tecnologias aplicadas, manifestam um potencial significativo de penetração nos regimes tecnológicos vigentes em diversas indústrias. Essa característica denota uma perspectiva de catching-up na indústria de software em países subdesenvolvidos, que surge com a possibilidade de se promover a difusão de soluções pré-fabricadas orientadas para o mercado interno, cujos custos amortizados já tenham sido cobertos por iniciativas de prestação de serviços, observados os dispositivos de lei que incidem sobre o setor. 


\section{Perspectivas conclusivas: caminhos e argumentos para as aspirações desenvolvimentistas multidimensionais em setores de alta intensidade tecnológica}

Entre os diversos caminhos que poderiam conduzir a conclusão deste trabalho, escolhe-se um em especial, o qual privilegia o debate sobre quais políticas seriam aplicáveis, em detrimento daqueles sobre o quanto seriam eficazes. E nessa linha, para aqueles que acreditam na força do capital e desconsideram a importância do trabalho, o que este artigo deixa como evidência é que não é possível afirmar que a intensidade de capital é o único determinante da adição de valor na indústria e, divergindo desta ideia e seguindo uma racionalidade objetiva, nota-se que o trabalho também é capaz de proporcionar adição substancial de valor e isso depende do processo de acumulação relacionado a cada indústria.

O leitor pode ter se perguntado, em algum momento durante a leitura deste artigo: é possível promover o emparelhamento da indústria de software em países subdesenvolvidos? Essa questão possui uma resposta deveras complexa, que precisa ser bem trabalhada e seria prematuro e talvez leviano responder a tal questão baseando-se simplesmente nas poucas linhas deste trabalho, mesmo porque esta não é a intenção principal. Entretanto, deixa-se como constatação que a história das indústrias de países subdesenvolvidos que realizaram catching-up foi fortemente marcada pela intervenção estatal. Nesse caso, não se confunda o sucesso com "o quanto o Estado é intervencionista" - isso já se demonstrou ser insuficiente como solução para os problemas de desenvolvimento (EVANS, 2004) -, mas observe, sobretudo, "quais as formas de intervenção" assumidas para o desenvolvimento.

Esse argumento não é tão simples e se encaixa sobre a contestabilidade da teoria das vantagens comparativas. É bastante improvável que o ambiente de países subdesenvolvidos consiga alavancar uma conspiração multidimensional sem a intervenção do Estado. A justificativa para uma postura neoliberal não se sustenta, pois há indícios de que as coisas não funcionam bem desta forma.

Partindo dessa necessidade, é possível transformar o ambiente nacional com novas competências produtivas? E as evidências empíricas para isso? Poder-se-ia ainda argumentar que alguns governos têm excluído o setor de TIC da lista de setores para a concessão de novos incentivos, pois já lhe é concedido um volume imenso de bonificações. Está aí o mérito da questão: não se trata, então, de uma oportunidade incrementar as isenções no setor, pois estaríamos providenciando uma perda de "bem-estar"? 
Os dados apresentados no corpo do trabalho mostram justamente o contrário, principalmente porque existem outros aspectos sociais e econômicos relacionados a setores de alta intensidade tecnológica que servem de justificativas contundentes para a intervenção estatal.

O que concluímos com isso? O argumento do custo de oportunidade remete o foco analítico para as condições de eficiência produtiva, deixando de lado as possibilidades futuras de desenvolvimento por meio de investimentos em novos setores. Ou seja, a avaliação do custo de oportunidade deve tomar como referência não só a condição presente do ambiente produtivo, mas, sobretudo, as possibilidades futuras de desenvolvimento e sustentabilidade. Talvez a melhor resposta para o argumento de Krugman e Obstfeld (1999) - em sua $4^{a}$ edição - sobre a desejabilidade dos setores de alta tecnologia venha dos próprios autores. O fato é que o argumento original é mal formulado e sem evidências empíricas reais. $\mathrm{Na} 6^{\mathrm{a}}$ edição de sua obra, Krugman e Obstfeld (2007, p.207) reformulam o argumento, apresentando uma postura mais cautelosa, admitindo inclusive a possibilidade de materialização de benefícios sociais por conta dos setores de alta tecnologia. Entretanto, permanece o problema das evidências empíricas. Por isso, inserimos dados da época do argumento (1991) e avaliamos as condições atuais sobre a adição de valor. A forma pela qual os autores apresentam a hipótese é insustentável. Implicitamente, eles se denunciam ao reformular o argumento.

Embora tenhamos, por razões metodológicas, nos reservado da execução de comparaçóes transversais entre os dados das Tabelas 3 e 4, uma breve análise pode revelar algo bastante perturbador: as diferenças de adição de valor entre a indústria brasileira e a americana. O achado de Roselino (2006) diz respeito à diferença de adição de valor entre empresas nacionais e estrangeiras dentro do Brasil e aqui foram observados indícios de que as diferenças persistem e são mais acentuadas comparando-se empresas brasileiras com outras que se encontram externamente ao Brasil, um resultado típico do efeito país (o que suscita a necessidade de uma investigação posterior mais aprofundada devido às limitaçōes metodológicas).

Acreditamos, portanto, que o problema não está na escolha do setor a se investir, mas sim na incapacidade do Estado em definir prioridades e determinar os mecanismos e as formas de intervenção em longo prazo, que possam se traduzir em desenvolvimento e, no caso específico da indústria de software, proporcionar ganhos de escala compatíveis com um padrão internacional de acumulação.

As isençôes nos setores de alta intensidade tecnológica, apesar de implicarem perda de arrecadação, podem fomentar a criação de novos postos de trabalho, o 
surgimento de benefícios sociais, o aumento do PIB, entre outros, que significam recuperação da arrecadação. Entretanto, quais seriam os entraves para uma ampla ação desenvolvimentista do setor em países subdesenvolvidos? Por conta da intensidade de trabalho, fatalmente, a resposta seria: a formação da mão de obra. Percebe-se que, na conjuntura econômica atual e diante das condições precárias de acesso a capital nas economias subdesenvolvidas, as vantagens comparativas mais próximas são as naturais ou aquelas pouco intensivas em capital. Pensando em termos da indústria de software, qual seria a vantagem comparativa? As características da indústria nos levam a concluir sobre a educação e a especialização do trabalho. Admitindo a importância desses fatores, tendemos a sugerir algo além: os domínios de aplicação das tecnologias, que são verdadeiras fontes de assimetria e podem constituir consideráveis barreiras à entrada no setor. Entretanto, necessitar-se-ia do estabelecimento de barreiras regulatórias que inibissem a migração de mão de obra ou preservassem efetivamente a propriedade intelectual, o que não é tão simples ou factível!

Sobre as externalidades, o que justifica a evolução dos postos de trabalho na indústria de software? Uma possível resposta a isso é que o próprio crescimento dos demais setores industriais promove a geração de emprego na indústria de software, devido às suas características de transversalidade e convergência, que têm garantido usos cada vez mais diversos e intensos do software em processos produtivos e organizacionais.

O que a convergência tecnológica representa em termos de desenvolvimento? No caso do software representa a oportunidade de aceleração do fluxo produtivo e a possibilidade de ganhos de escala em rede, provocando uma série de externalidades na economia, sendo uma delas a geração de emprego. Isso é um efeito inverso do que certamente ocorre com a indústria química e petroleira (no caso americano), podendo ser justificado pela ocorrência de crescimento sem emprego.

Os argumentos aqui apresentados impõem limitações contundentes ao pressuposto das vantagens comparativas e à tese de que a intensidade de capital seria determinante do alto valor por trabalhador na indústria. Portanto, não se pode simplesmente renunciar aos esforços de desenvolvimento dessa indústria, pois também lhe são cabíveis justificativas sociais. Não se trata apenas de depender de fornecedores estrangeiros de equipamentos e softwares, mas também da capacidade da indústria em gerar externalidades positivas materializadas por esses benefícios e pelo retorno econômico que são importantes justificativas para empresários e governo empreenderem ações que constituem uma conspiração multidimensional desenvolvimentista. 
Por fim, apresenta-se uma breve consideração sobre "quais intervençôes?". $\mathrm{Na}$ limitada visão que as linhas deste trabalho trazem, acreditamos que a política industrial não deva ser endereçada aos problemas urgentes da indústria de software que aqui foram traduzidos pela intensificação da convergência tecnológica, pelo incremento da adição de valor e pela geração de externalidades. Isso tudo representa aparências construídas no seio do modo de produção capitalista e, combatendo simplesmente as distorções nessas aparências, sem verificar suas fundamentações ideológicas, não se chegará sequer a um limiar diferencial de desenvolvimento industrial capaz de provocar efeitos colaterais positivos.

Há um mito perverso e perigoso de que empresas podem nascer pequenas, se fortalecer, crescer e despontar como grandes agentes de transformação. Na indústria de software, as barreiras de crescimento para pequenas empresas são contundentes e a mais significativa se relaciona ao acesso e ao uso de conhecimentos. A questão que se endereça aqui está nas possibilidades de a política industrial intervir nos processos de geração, retenção e distribuição de conhecimento, que, na perspectiva destes autores, seria a intervenção mais elementar e sublime em prol de uma transformação industrial virtuosa e não virtual.

\section{Referências bibliográficas}

AMSDEN, A. H. Asias's next giant: South Korea and late industrialization. New York: Oxford University Press, 1989.

BEA - Bureau of Economic Analysis. Gross domestic product by industry accounts. Disponível em: <http://www.bea.gov/>. Acesso em: 01 ago. 2007.

BESSEN, J.; HUNT, R. M. An empirical look at software patents. 2004. (Working Paper n. 03-17/R). Disponível em: <http://www.researchoninnovation.org/swpat.pdf>. Acesso em: 12 abr. 2008.

BLS - Bureau of Labor Statistics. National industry-specific occupational employment and wage estimates. May 2008. Disponivel em: <http://www.bls.gov>. Acesso em: 28 maio 2009.

BRANCO, C. E. C.; MELO P. R. de S. Proposta de atuação para o BNDES no setor de software. Disponível em: .<http://www.bndes.gov.br/conhecimento/bnset/ sofset02.pdf>Acesso em: 10 fev 2003.

CARNEIRO, A. M. Proteção de ativos na indústria de software: estratégias e tendências de Propriedade Intelectual. Campinas: Instituto de Geociências - Departamento de Política Científica e Tecnológica, Universidade Estadual de Campinas, 2007. 
CASTELlS, M. A sociedade em rede. São Paulo: Paz e Terra, 2003.

CHANDLER, A. D. Scale and scope. Massachusetts: Harvard/Belknap, 1990.

CHANG, H. J. Chutando a escada - a estratégia do desenvolvimento em perspectiva histórica. São Paulo: Unesp, 2004.

CIMOLI, M.; DOSI, G.; NELSON, R. R.; STIGLITZ, J. Instituições e políticas moldando o desenvolvimento industrial. RBI, Rio de Janeiro, Finep, v.6, n.1, p.55-85, 2007.

EVANS, P. Autonomia e parceria. Rio de Janeiro: UFRJ, 2004.

FREEMAN, C. Inovação e ciclos longos de desenvolvimento econômico. Porto Alegre, 1984.

FREEMAN, C.; SOETE, L. The economics of industrial innovation. Massachusetts: MIT Press, 1997.

GAIO, F. The development of computer software technological capabilities in developing countries: a case study of Brazil. 1990. Thesis (Doctor of Philosophy) - Sussex, April 1990.

GILPIN, R. The politic economy of international relations. Princeton, NJ: PRU, 1987.

GOLDENSTEIN, L. Repensando a dependência. Rio de Janeiro: Paz e Terra, 1994.

HATZICHRONOGLOU, T. Revision of the high-technology sector and product classification. Paris: OCDE, 1997.

HEEKS, R.; NICHOLSON, B. Software export success factors and strategies in developing and transitional economies. Paper n. 12/2002. Disponível em: <http://www.man.ac.uk/idpm/ idpm_dp.htm\#devinf_wp>. Acesso em: 10 jan. 2003.

HIRSCHMAN, A. A generalized linkage approach to development, with special reference to staples. Economic Development and Cultural Change, n.25, p. 67-97, 1977.

IBGE. Pesquisa de Inovação Tecnológica - Pintec 2005. Rio de Janeiro, 2007. Disponível em: <www.ibge.gov.br>. Acesso em: 30 jul. 2007.

Pesquisa Anual de Serviços 2006. Rio de Janeiro, 2006a. Disponível em: <www. ibge.gov.br>. Acesso em: 22 maio 2009.

Pesquisa Industrial Anual 2006. Rio de Janeiro, 2006b. Disponível em: <www.ibge. gov.br>. Acesso em: 22 maio 2009.

KIM, L. Da imitação à inovação. Campinas: Unicamp, 2005.

KONCZ, J.; MANN, M.; NEPHEW, E. U.S. international services. Disponível em: <http:// www.bea.gov>. Acesso: 05 set. 2007.

KRUGMAN, P. R.; OBSTFELD, M. Economia internacional: teoria e política. 4a Ed. São Paulo: Makron Books, 1999. 
Silvio Vanderlei Araújo, Alisson Santos de Sousa, Emerson Wilian Araújo

Economia internacional: teoria e política. São Paulo: Makron Books, 2007.

KUMAR, K. Da sociedade pós-industrial à pós-moderna. Rio de Janeiro: Jorge Zahar, 1997.

LIST, F. Sistema nacional de economia política. São Paulo: Abril Cultural, 1983.

McFARLAN, F. W. A tecnologia da informação muda a sua maneira de competir. In: MONTGOMERY, C. A.; PORTER, M. E. Estratégia. Rio de Janeiro: Elsevier, 1998.

MODY, A. Strategies for developing information industries. In: COOPER, C.; KAPLINSKY, R. Technology and development in the third industrial revolution. London: Frank Kass, 1989.

NSF - National Science Foundation. Science and engineering indicators 2006. Disponível em: <http://www.nsf.gov>. Acesso em: 07 set. 2007.

OECD. ICT Outlook 2006. Disponível em: <http://www.oecd.org>. Acesso em: 25 jul. 2007.

OZAKI, R. S. How japanese industrial policy works. In: JOHNSON, C. (Ed.). The industrial policy debate. San Francisco, CA: ICS Press, 1984.

PAVITT, K. Patent statistics as indicators of innovative activities: possibilities and problems. Scientometrics Vol. 7. Nos 1-2. p. 77-99. 1985.

PEREZ, C. A onda atual de mudança tecnológica. Washington: Banco mundial, 1989.

Changement technologique et opportunités de développement: une cible mouvante. Revista de la CEPAL. Número especial. 2005.

PREBISCH. R. O desenvolvimento econômico da América Latina e alguns de seus principais problemas. 1949. p. 69 - 136. In: BIELSCHOWSKY, R. Cinqüenta anos de pensamento na Cepal. v1. Rio de Janeiro: Record, 2000.

Dinâmica do desenvolvimento latino-americano. São Paulo: Fundo de Cultura,

1964.

MTE - Ministério do Trabalho e Emprego. Relação Anual de Informações Sociais - Rais. 2007. Disponível em: <www.mte.goc.br/pdet>. Acesso em: 28 maio 2009.

RICARDO, D. Princípios de economia política e tributação. São Paulo: Abril Cultural, 1982.

ROSELINO, J.E. A indústria de software. Tese (Doutorado). Campinas: Unicamp, 2006.

ROSENBERG, N.; BIRDZELL. L.E. A história da riqueza do ocidente: a transformação econômica do mundo industrial. Rio de Janeiro: Record, 1986.

ROUSSEVA, R. Technological capabilities with different degree of coherence: a comparative study of domestic-oriented vs. export-driven bulgarian software companies. 2006. Disponível em: <http://www.merit.unu.edu>. Acesso em: 10 fev. 2007. 
SCHUMPETER, J. A teoria do desenvolvimento econômico. São Paulo: Abril Cultural, 1982.

SHAPIRO, C.; VARIAN, H. R. Information rules. Massachusetts: HBS Press, 1999.

USPTO (U.S. Patent). Ranked listing of organizations with patent grants. Disponível em: <http://www.uspto.gov/web/offices/ac/ido/oeip/taf/apat.pdf>. Acesso em: 07 set. 2007.

VEIGA, R. Atividades de desenvolvimento de software: uma análise das possibilidades de inclusão social Dissertação (Mestrado). Campinas: Departamento de Política Científica e Tecnológica - Instituto de Geociências, Universidade Estadual de Campinas, 2008.

ENDEREÇOS PARA CORRESPONDENCIA:

Silvio Vanderlei Araújo - suander@ufba.br Universidade Federal da Bahia, Escola de Administração

Av. Reitor Miguel Calmon, s/n, Vale do Canela

41100-903 - Salvador (BA)

Tel: (71) 3283-7338, Fax: (71) 3293-7339

Alisson Santos de Sousa - alisousa@gmail.com

Secretaria de Ciência, Tecnologia e Inovação do Estado da Bahia

Rua Dr. Renato Mendonça, 134, ap. 302, Brotas

40285440 - Salvador (BA)

Tel: (71) 9171-0907

Emerson Wilian Araújo - emersonwilian@gmail.com

Fundação Visconde de Cairu

Rua do Salette, 50, Barris

Salvador (BA)

Tel: (71) 3353-1289 